\title{
A GESTÃO DO CONHECIMENTO E VANTAGENS COMPETITIVAS: ANÁLISE DE METODOLOGIAS DE IMPLANTAÇÃO
}

\author{
Adelaide M.C. Baêta
}

MPA, Fundação Pedro Leopoldo

\author{
Ângela M.R. Martins
}

MPA, Fundação Pedro Leopoldo

Fávia mM.C. Baêta

MPA, Fundação Pedro Leopoldo

\section{RESUMO}

O objetivo deste artigo é avaliar os impactos das metodologias adotadas, atualmente, por algumas empresas brasileiras e internacionais para implementar a gestão do conhecimento na condução do processo de inovação e, conseqüentemente, seus efeitos nos resultados do projeto. A tônica deste trabalho é enfatizar a importância da democratização do conhecimento e da percepção de sua aplicabilidade pelos funcionários. A pesquisa realizou-se por meio de entrevistas, análise documental e um estudo comparativo. A partir de uma revisão das principais tendências para a abordagem do tema, é feita uma análise de diferentes processos metodológicos utilizados. A confrontação das aplicações empresariais apresentadas revela como a estratégia para a criação de um ambiente propício ao compartilhamento é fator preponderante para o sucesso de um empreendimento, que tem como principal recurso o capital humano. Neste sentido, a escolha da metodologia mais adequada à cultura da organização influencia de forma significativa o comportamento dos colaboradores, que são a fonte primeira do conhecimento organizacional. As conclusões apontam que a metodologia que privilegia esses conceitos - democratização e aplicabilidade - favorece o compartilhamento e concorre para a obtenção de vantagens competitivas.

\section{INTRODUÇÃO}

O propósito deste artigo é avaliar os impactos dos procedimentos que estão sendo adotados pelas organizações, na gestão do conhecimento, com vistas a alcançar vantagens competitivas. Neste trabalho uma ênfase é dada à democratização para o compartilhamento. Outro aspecto analisado é a percepção da aplicabilidade do conhecimento pelos colaboradores como fator motivacional para a transferência do conhecimento. A pesquisa realizou-se por meio de análise documental e entrevistas para um estudo comparativo.

O estudo baseou-se na comparação das experiências de empresas multinacionais apresentadas na pesquisa realizada por NIKLAS ARVIDSSON (2002) com a experiência de uma empresa brasileira de grande porte. Todas as empresas objeto desta análise caracterizam-se como organizações descentralizadas uma vez que operam em diversos países, onde a necessidade de comunicação e compartilhamento é muito maior. As empresas descentralizadas exemplificam de forma mais incisiva as exigências das organizações da era do conhecimento. 
A partir de uma revisão das principais tendências para a abordagem do tema, é feita uma análise dos procedimentos utilizados para a transferência do conhecimento na busca da compreensão das condições ambientais que favorecem o sucesso da implantação da gestão do conhecimento.

A confrontação das experiências apresentadas revela como a estratégia para a criação de um ambiente propício ao compartilhamento é fator preponderante para o sucesso de um empreendimento, que tem como principal recurso o capital humano.

$\mathrm{Na}$ atual sociedade, onde o conhecimento está ganhando importância como fonte para vantagem competitiva a habilidade das organizações de capitalizar suas próprias competências tornou-se essencial.

Os novos modelos de organização são compatíveis com uma visão da empresa como um sistema de conhecimento distribuído, no qual os indivíduos são engajados na tarefa de criar, de partilhar e de transformar o conhecimento. Entretanto, há algumas características essenciais que podem ser vistas como componentes potencialmente críticos para que as organizações competitivas operacionalizem mudanças contínuas por meio da gestão do conhecimento e da aprendizagem (TERRA, 2000; TEECE, 2000; PETER TYNDALE, 2001).

empresa multinacional é um dos fenômenos de maior sucesso da era moderna. Uma das razões da multinacional ter tanto sucesso é sua habilidade única de transferir recursos em escala global, porém dentro das fronteiras da própria organização (BUCKLEY; CASSON, 1976). De fato, a raisond'être da multinacional é a sua capacidade de combinar vantagens regionais, tais como insumos e mão-de-obra baratos, com vantagens específicas da organização, tais como marcas, tecnologias e patentes (DUNNING 1977, 1980). Desta forma, a multinacional se beneficia simultaneamente das vantagens de diferentes regiões do mundo, e as combina com sua poderosa capacidade de produção de processos e produtos. Em resumo, a maior vantagem da multinacional é sua habilidade de transferir recursos e conhecimentos através de distâncias geográficas.

Para a análise dos procedimentos de implantação das práticas de gestão que concorrem para a transferência do conhecimento pelas organizações, este estudo está estruturado da seguinte forma: a seção 2 apresenta o referencial teórico que descreve algumas abordagens dos estudos de gestão do conhecimento; a seção 3 identifica os aspectos metodológicos da implantação da gestão do conhecimento; a seção 4 apresenta algumas condições da transferência do conhecimento nas empresas descentralizadas; a seção 5 analisa as experiências das organizações na criação do ambiente para a transferência do conhecimento; a seção 6 mostra as conclusões do trabalho e a seção 7 faz referência à bibliografia utilizada.

\section{ABORDAGENS DOS ESTUDOS DE GESTÃO DO CONHECIMENTO}

Pode-se dividir os estudos de gestão do conhecimento em duas grandes vertentes. Uma que é voltada para a tecnologia da informação e que tem como foco central a criação de infra-estrutura para a transferência, a sistematização e o estoque das informações (banco de dados, intranet etc). Outra vertente aborda o conhecimento de uma perspectiva social que estabelece uma distinção entre informação e conhecimento, e cujo foco é a criação do ambiente que favorece a comunicação, a confiança e as condições necessárias à produção e transferência do conhecimento.

Uma outra perspectiva relaciona-se ao entendimento da gestão do conhecimento como busca de equilíbrio na relação entre a utilização de experiências adquiridas e a exploração de novos conhecimentos. MARCH (1991) corrobora afirmando que uma questão central nos estudos de processos adaptativos é a relação entre a exploração de novas possibilidades e a utilização de velhas certezas. Compreende-se por exploração, num sentido amplo, recursos capturados pela pesquisa, 
variação, experimentação, flexibilidade, descoberta e inovação; enquanto a utilização inclui a escolha, o refinamento, a seleção, a produção, a implementação e a execução. A tendência é enfatizar-se mais a utilização do que a exploração. MARCH (1991) adverte que tal tendência a longo prazo pode ser uma desvantagem competitiva para as organizações. Torna-se, pois, essencial perceber que a gestão do conhecimento deveria orientar-se no sentido de valorizar a exploração de novos conhecimentos tendo em vista a vantagem competitiva, além de usufruir o acervo de experiências acumuladas. Segundo CARLSSON (2001) ganhar e sustentar uma vantagem competitiva através da gestão do conhecimento é um processo que envolve: visão estratégica, visão do conhecimento apropriado, identificação do conhecimento chave, proteção do conhecimento, projeto, implementação e aplicação.

CAVES (1971), HYMER (1976) e DUNNING (1977) chamam a atenção para o fato de que, inicialmente, a tecnologia baseada em conhecimento era o principal tema das pesquisas sobre conhecimento em multinacionais Como conseqüência, as pesquisas tinham foco na inteligibilidade do conhecimento, isto é o grau no qual era possível codificar e documentar conhecimento de tal forma que outros pudessem entender e usar o conhecimento existente na empresa (ZANDER, 1991). A organização podia se proteger contra a imitação dos competidores por meio de suas patentes. Hoje, o conhecimento orientado a atividades não tecnológicas - tais como logística, controle de qualidade, ou marketing - tem se tornado cada vez mais importante (KOSTOVA, 1996). Porém o conhecimento está sempre localizado nas mãos e nas mentes de pessoas.

Outra consideração importante nos estudos de gestão do conhecimento relaciona-se à necessidade da organização de integrar se ao ambiente, para responder às exigências da "Sociedade do Conhecimento".

TERRA (2002) nos adverte:

"Vivemos em um ambiente de mudanças rápidas, em que os sinais de surgimento de uma sociedade do conhecimento são muito fortes e a gestão pró-ativa dos recursos do conhecimento é parte fundamental do crescimento dos negócios. Isso nem sempre foi assim”.

A gestão do conhecimento pode ser entendida como uma estratégia de integração dos ativos intelectuais de uma organização - informações registradas e os talentos de seus colaboradores convertidos em maior produtividade, inovação e aumento de competitividade, mediante aperfeiçoamento de habilidades em uma entidade coletiva. Nesta concepção, o conhecimento está relacionado à sua aplicabilidade transformadora. Portanto, conhecimento é informação transformada em capacidade por meio de ações efetivas que se convertem em soluções. $\mathrm{O}$ foco da gestão do conhecimento, sob esse prisma, pode ser interpretado como a criação de condições viabilizadoras para que o conhecimento dos indivíduos seja transformado em ação inovadora. A questão central é como o conhecimento é adquirido e como pode ser usado na geração de resultados condizentes com as necessidades da empresa (BAÊTA et al, 2001; CISALPINO, 2002; FERREIRA E VASCONCELOS,2001).

O conhecimento sempre começa com o indivíduo, conseqüentemente ele é pessoal, porque alguém faz uma descoberta. O objetivo da gestão do conhecimento é fazer com que esse conhecimento se torne disponível para outros (NONAKA, 1991; DAVENPORT \& PRUSAK, 1998).

O conhecimento não aplicado tem pouca utilidade para a alavancagem de vantagem competitiva. Por esta razão, o foco da gestão do conhecimento é transformar o conhecimento individual em conhecimento organizacional. Para tanto, as organizações devem ser capazes de desenvolver um ambiente favorável à geração do conhecimento tácito e simultaneamente convertê-lo em conhecimento organizacional e know-how. A valorização da aprendizagem organizacional surge 
nesse contexto. Um problema do conhecimento tácito é que nem sempre quem o detém consegue articulá-lo.

No processo de aprendizagem os estudiosos assinalam a relevância dos aspectos ambientais para o compartilhamento e transformação do conhecimento tácito em organizacional. Apontam como condições essenciais para incentivar a aprendizagem a democratização das informações, o compartilhamento dos objetivos, a visão sistêmica da organização e a ação monitorada (SENGE, 1990; PETERS, 1993; WICK \& LEON, 1995).

A democratização da informação está relacionada ao livre acesso às informações, à variedade de fontes de informação e de processos e aos mecanismos de disseminação da informação. SENGE (1990) assinala a importância da "visão sistêmica", essencial à auto-regulação - capacidade da empresa de processar e adequar seus resultados - de acordo com os feedbacks que recebe, como intercâmbio entre os colaboradores da empresa; da redundância decorrente do rodízio de funções e das relações e intercâmbios entre mercado e ambiente. $\mathrm{O}$ autor enfatiza também a necessidade da ação monitorada que privilegia os aspectos relativos ao planejamento como integração; à experimentação e viabilização de idéias, aos benefícios de um programa de educação e treinamento e ao acompanhamento do desempenho individual das pessoas e das mudanças.

\section{OS ASPECTOS METODOLÓGICOS NA GESTÃO DO CONHECIMENTO}

A metodologia de implantação de um projeto de gestão do conhecimento é um fator essencialmente crítico para o sucesso da aprendizagem organizacional.

De acordo com TEIXEIRA FILHO (2000), todos projetos de implantação de gestão do conhecimento como quaisquer outros projetos complexos envolvem o controle de diversos fatores considerando que pertencem à categoria de processos de mudança de alto impacto e larga escala.

Por se tratar de um campo de estudos em desenvolvimento a gestão do conhecimento ainda não consolidou metodologias em que os estudiosos desse assunto possam se apoiar para a análise de sua implantação. Todavia, é possível identificar alguns procedimentos adotados pelas organizações na condução do processo. A expressão metodologia é entendida aqui como o conjunto de procedimentos ou o caminho escolhido pela organização para propiciar a comunicação, a confiança e as condições necessárias à produção e à transferência do conhecimento.

\section{A TRANSFERÊNCIA DO CONHECIMENTO}

As empresas competitivas que operacionalizam operações contínuas, principalmente por meio da gestão do conhecimento, têm uma visão diferenciada da relação entre a organização e o ambiente. $\mathrm{O}$ ambiente, para a organização que gerencia o conhecimento, é visto como parte da teia integrada na qual se configuram ambas entidades, sem a tradicional divisão entre a realidade da organização e o ambiente como situações antagônicas (TEECE, 2000; PETER TYNDALE, 2001).

Como resultado das mudanças na abordagem da gestão do conhecimento os estudos de transferência de best practices se tornaram constantes. NIKLAS ARVIDSSON (2000) analisa as dificuldades da transferência do conhecimento enfatizando que nem sempre o conhecimento é facilmente articulado e, além disso, para fazê-lo fluir são necessárias condições específicas, o que muitas vezes, não é compreendido pelas organizações. 
As organizações descentralizadas têm subsidiárias ou unidades em diferentes partes do mundo. Estas unidades são influenciadas tanto pela cultura da própria organização quanto pelo ambiente da sua localização. Sua rede local é uma fonte importante para o desenvolvimento de competências específicas. O segredo de transferir tais competências, que encontram-se dispersas, reside na organização interna e na integração das diversas unidades. Isto inclui a habilidade da empresa de construir sistemas de informação que promovam a transferência de práticas, e a habilidade da organização para criar valores compartilhados que promovam discussão e solução de problemas entre departamentos e subsidiárias. Pesquisas mostram também que a transferência depende da habilidade de aprendizagem do receptor (SZULANSKI, 1996), do relacionamento entre as partes no processo de transferência (KOSTOVA, 1996), e das características próprias do conhecimento (ZANDER, 1991).

\section{UMA ANÁLISE COMPARATIVA}

\section{A experiência de empresas multinacionais -}

NIKLAS ARVIDSSON (2000) realizou um estudo sobre a gestão do conhecimento em multinacionais. Sua análise tem foco em uma questão considerada por ele como a mais fundamental com relação à transferência do conhecimento: as empresas e os gerentes são capazes de identificar quais subsidiárias são fontes de transferência de processos de best practices, de forma que a que tenha menos capacitação possa aprender com a que detenha mais?

Duas questões subjacentes orientaram sua pesquisa. Primeiramente, os gerentes da corporação e das subsidiárias avaliam as competências de uma subsidiária de forma consistente? Em segundo lugar, as avaliações explicam a escolha das fontes e receptores no processo de transferência do conhecimento? Ele coletou dados empíricos de duas maneiras diferentes, mas complementares. Dados qualitativos foram coletados para se fazer um teste preliminar dos temas que governam o estudo e para permitir a compreensão do fenômeno. Dados quantitativos foram coletados em sete empresas suiças - Skandia, Sandvik Coromant, Sandvik Steel, Ericsson, Volvo, Pharmacia \& Upjohn e Alfa Laval Agri. Este número de empresas é significativo para projetar conclusões consistentes.

Como resultado da pesquisa qualitativa, AVIRDSSON (2000) concluiu que a corporação e as subsidiárias freqüentemente têm opiniões diferentes sobre quão capaz uma subsidiária é. Enquanto os gerentes da corporação disseram que eles queriam aproveitar a base de conhecimento de suas subsidiárias, os gerentes das subsidiárias freqüentemente sentiam que as idéias deles não eram bem recebidas na corporação. O dilema é encontrado na maioria das multinacionais. Além disso, boas idéias que são desenvolvidas na corporação podem receber um tratamento preconceituoso pelos gerentes operacionais nas subsidiárias.

Uma das empresas pesquisadas utilizou a criação de centros de excelência como um passo metodológico com o propósito de alavancar capacitações específicas na Europa. Inicialmente, tudo funcionou bem. Sete departamentos ou subsidiárias foram escolhidos como centros de excelência em áreas como aferição da fidelização de clientes, marketing focado em clientes, e gerenciamento estratégico. Eles estavam localizados na Alemanha, Inglaterra, Suíça e França. À medida que os centros de excelência foram estabelecidos, eles se tornaram entidades independentes. Entretanto, eles continuaram no orçamento dos países nos quais estavam lotados. Mas o sistema provou ser de difícil gerenciamento. Os projetos dos centros de excelência nunca receberam orçamentos próprios. Ao invés disso, os diretores nacionais tinham que incluir estes custos em seus orçamentos. Por outro lado, as receitas que o centro de excelência gerava, freqüentemente beneficiavam subsidiárias de outros países. 
O efeito da combinação da internalização de custos e externalização de receitas não teve sustentação. O conflito orçamentário inviabilizou o projeto. Um diretor simplesmente disse que o centro de excelência devia trabalhar exclusivamente com as unidades de um determinado país.

Um segundo problema se relacionava ao tema de quão valiosos eram realmente os conhecimentos dos centros de excelência para as unidades operacionais de outros países. A decisão de quais unidades deveriam funcionar como centros de excelência foi responsabilidade de um único executivo, o que provocou disputas entre os centros.Os gerentes das subsidiárias algumas vezes ignoravam os centros de excelência e contratavam consultores externos que forneciam orientações diferentes. Por fim, um estudo interno mostrou que após dois anos o início das atividades dos centros de excelência, menos de $10 \%$ dos funcionários europeus conheciam sua existência e menos que $2 \%$ conheciam o que realmente eles faziam.

Uma outra empresa utilizou como procedimento metodológico a priorização de uma solução baseada em IT/IS, e desenvolveu um sistema global de informações para funcionar primeiramente como provedor de informações, mas com a expectativa de se criar um banco de dados de experiência e conhecimento. A expectativa era que os vendedores armazenassem experiências e soluções de problemas específicos que eles encontrassem durante o curso de seu trabalho. A experiência desta empresa foi de que o sistema manuseava transferência de informação muito bem. Transferência de conhecimento, entretanto, não ocorreram.

Em uma das empresas pesquisadas, os gerentes da corporação e das subsidiárias tinham interpretações muito diferentes de como as coisas eram realmente.

Os resultados indicaram um grande gap de percepção, isto é diferenças sobre como os gerentes da corporação e das subsidiárias avaliam as competências. Porém, as avaliações referentes a performance financeira, o padrão foi muito diferente das avaliações de competência. Havia um nível de concordância muito mais alto entre as avaliações de performance financeira do que com relação às avaliações de competência. Um dos equívocos da seleção das unidades fontes de transferência é que normalmente são indicadas aquelas que têm melhor desempenho financeiro.

A principal conclusão do estudo de ARVIDSSON(2000) é que a gestão do conhecimento centralizada na matriz, isto é na corporação, mediante ações hierarquicamente controladas não funciona. $\mathrm{O}$ conhecimento reside nas mãos e nas mentes dos gerentes operacionais e pode ser mais bem avaliado por eles. Não se pode gerenciar o que não se compreende. O risco é que a seleção das unidades fontes seja fortemente influenciada pelo desempenho financeiro. Pode ocorrer que uma avaliação adequada das competências de uma subsidiária não esteja relacionada com o seu desempenho financeiro e o que se constata é que os gerentes corporativos não têm consciência desta discrepância.

\section{O CASO DA EMPRESA BRASILEIRA}

A Andrade Gutierrez é uma empresa da área de construção civil que opera em diversos países. A análise da experiência da gestão do conhecimento nesta empresa obteve resultados muito diferentes dos apontados na pesquisa realizada por ARVIDSSON (2000) em empresas multinacionais.

A experiência da Andrade Gutierrez em gestão do conhecimento teve início quando a empresa sofreu um prejuízo da ordem de milhões de dólares, na década de 90, durante a execução de uma obra que estava sendo realizada na Bolívia. A pavimentação da estrada que estava sendo construída trincou devido a condições do clima e do solo da região dos Andes. Isto havia ocorrido no Peru alguns anos antes e a empresa já detinha o know-how aplicável ao processo de pavimentação para aquelas condições geológicas específicas. A empresa já havia pago um alto custo por aquele aprendizado. Era inadmissível não potencializar seu conhecimento aplicando-o à força de trabalho. 
Era preciso ter um diferencial competitivo consistente em relação aos concorrentes. Um dos principais executivos da empresa constatou que o compartilhamento do conhecimento da organização vinha sendo feito informalmente. Quando se ganhava uma concorrência, ele ou algum diretor mais antigo solicitava ao gerente do novo projeto que trocasse idéias com o engenheiro que havia sido responsável por outra obra semelhante. Não havia um acervo das experiências adquiridas. Nessa ocasião, os dirigentes da construtora decidiram implantar a gestão do conhecimento.

A empresa acredita que a infra-estrutura de um sistema de gestão do conhecimento não é o problema mais crítico, uma vez que ela pode ser "comprada", o grande desafio é a preparação de um ambiente propício ao compartilhamento. A gestão do conhecimento necessita de uma cultura que precisa ser considerada, além da tecnologia. No início, a empresa enfrentou grandes dificuldades. A primeira foi decidir o que era realmente o conhecimento chave para a construtora. A organização pretendia coletar conhecimento, não informação. $O$ interesse era armazenar o conhecimento baseado na experiência. Assim, a construtora decidiu pela captura dos conhecimentos dos seus colaboradores e por torná-los disponíveis para compartilhamento e reutilização.

Para a primeira fase do sistema, foram adotados três campos de conhecimento, que refletiam o core business: execução de obras, construção e gestão do risco. Os funcionários preenchiam os formulários, descrevendo a sua biografia e davam entrada no sistema pela internet. Para a implantação da gestão do conhecimento foram disponibilizados trainees com experiência na digitalização de informações para apoiar os funcionários que queriam contribuir, mas que não tinham familiaridade com computadores.

O sistema tem instrumentos que fazem um mapeamento para apontar quem mais colabora na empresa e quem não tem contribuído. A gestão motivacional inclui palestras em obras onde os empregados não estão contribuindo apesar de identificados com grande potencial de colaboração. Anualmente, são distribuídos prêmios aos empregados que contribuíram mais e aos que contribuíram com os conhecimentos mais relevantes. Os prêmios são de diversas espécies. Os mais almejados são as viagens ao exterior com acompanhante e o valor equivalente ao de um Honda Civic.

Um exemplo da aplicabilidade e benefícios da gestão do conhecimento foi a obra de uma hidrelétrica.

"O insumo mais utilizado na construção de uma hidrelétrica é o cimento para fazer as fundações e o muro de contenção da barragem. Durante a etapa de concretagem houve uma contaminação de excesso de material fino de britagem de rocha (basalto). A decisão do cliente foi exigir que se refizesse todo o concreto porque ele não iria alcançar a resistência projetada. Além de refazer o concreto, a empreiteira teria que arcar com os altos custos de demolição, remoção e transporte de material. Um geólogo e um engenheiro da empresa analisaram o problema e, devido ao conhecimento e experiência de ambos, concluíram que $o$ pó fino de rocha da contaminação poderia reagir com o cimento e, sendo assim, o concreto alcançaria a resistência necessária, sem a necessidade de sua remoção. Após 28 dias, a resistência projetada foi alcançada. Com 90 dias, foi ultrapassada, mostrando que a contaminação havia sido benéfica. O pó deste tipo de rocha melhora o cimento, pois é mais um produto 'cimentar'”.

A partir deste aprendizado, a empresa vem "contaminando" propositalmente o concreto nas obras de hidrelétricas, o que reduz os custos consideravelmente. Este exemplo ilustra como até uma 
experiência mal sucedida pode ser transformada em uma inovação para alcançar vantagem competitiva.

\section{CONCLUSÃO}

A conclusão aponta que os procedimentos metodológicos que privilegiam a democratização e a aplicabilidade propiciam a criação de um ambiente favorável ao compartilhamento e influencia de forma significativa o comportamento dos colaboradores na transferência do conhecimento e capacitações. Não por acaso as organizações buscam gerenciar o conhecimento com ênfase na transformação do conhecimento tácito em conhecimento organizacional. Todavia essa não é uma tarefa simples. Algumas empresas, senão a maioria, enfrenta dificuldades para a implantação da gestão do conhecimento como se observa no caso das multinacionais pesquisadas.

Os obstáculos são de diversas naturezas. A pesquisa apontou que uma das dificuldades é a visão equivocada das organizações com relação ao foco da metodologia de implantação. A criação de centros de excelência pode reforçar a centralização, a hierarquia e dificultar o compartilhamento. O enfoque que busca eleger a unidade que utiliza a melhor prática (best practice) acaba por acirrar rivalidades e concorre muitas vezes para difundir práticas inadequadas.

Foi possível constatar na pesquisa a atuação da empresa na reutilização de conhecimentos adquiridos e na exploração de novas possibilidades, o que demonstra a ênfase na aplicabilidade do conhecimento para a vantagem competitiva. Os resultados da pesquisa mostram ainda que a empresa organiza e sistematiza as informações de modo a favorecer a identificação do conhecimento chave para as atividades da empresa e o fácil acesso dos funcionários ao sistema, o que garante o fluxo de transferência do conhecimento entre as várias unidades.

Pode-se concluir, portanto, com base na pesquisa realizada que não basta às empresas gerarem e organizarem o conhecimento, torna-se essencial criar condições para que o conhecimento seja compartilhado e efetivamente aplicado.

Finalmente, gostaríamos de sugerir novas pesquisas que pudessem aprofundar a análise das metodologias de implantação da gestão do conhecimento que levem a novas práticas de gestão.

\section{BIBLIOGRAFIA}

BAÊTA, A. M.C. (2001). Knowledge Management: The Experience of Science -Based Companies in Brazil. Proceedings of Second European Conference on Knowledge Management. Bled school of Management, Bled: Slovenia, November,8-9, 2001.

BAUMARD, P. (1999) Tacit Knowledge in Organiztions, London, Sage publications.

BROWN, J. S. \& DUGUID, P (1991). Organization Learning and Communities of Practice: Towards a Unified View of Working, Learning and Innovation, Organizations Science, Vol 2, pp 40-57.

CARLSON, S. et al. (2001). The Birth, Death and Resurrection of a Knowledge management Strategies. Proceedings of $2^{\text {nd }}$ European Conference on Knowledge Management, MCIL: Management Centre International Limited; Bled School of Management, Bled, Slovenia, november. 
CISALPINO Lais S. (2002) Learning Organization e Gestão do Conhecimento - Propostas para a Competitividade. 93 f. Dissertação (Mestrado Profissional em Administração) - Faculdade de Ciências Humanas de Pedro Leopoldo, Minas Gerais.

DAVENPORT, T \& PRUSAK, L. (1998) Working knowledge: how organization manage what they know. Boston, Mass: Harvard Business School Press.

FERREIRA, Marta \& VASCONCELOS, Maria Celeste R. L. (2001). The Practice of Knowledge Management in Industry. Proceeding of the $2^{\text {nd }}$ European Conference on Knowledge Management. MCIL:Management Centre International Limited; Bled School of Management, Bled, Slovenia, november, pp 695-704.

FLEURY. FLEURY, Afonso \& Maria Tereza Leme. Aprendizagem e inovação organizacional; as experiências do Japão, Coréia e Brasil. São Paulo: Atlas, 1997.

LEAVITT, H. J (1965). Applied Organizational Change in Industry: Structural, technological and humanistic approaches. In: Handbook of Organizations Chicago, J. G. March eds. Rand Mcnally.

LEWIN, K (1958). Group decision and social change. In: Reading in Social Psychology E. E. Maccoby, T. M. Newcomb, \& E. Hartley, L. (Eds.), New York, NY: Holt, Rinehart \& Winston, pp 197-211.

MARCH, J. G. (1991). Exploration and exploitation in Organization Learning. Organization Science, pp 1,71-87.

NONAKA, I \& TAKEUCHI, K (1995). The Knowledge Criating Company: How Japanese Companies Create the Dynamics of Innovation, Oxford, Oxford University Press.

PETER TYNDALE (2001). The Organizational Knowlwdge Development Life Cycle: From Knowledge Creation to Knowledge Application. Proceeding of the $2^{\text {nd }}$ European Conference on Knowledge Management. MCIL:Management Centre International Limited; Bled School of Management, Bled, Slovenia, november, pp 663-676.

PETERS, John. (1993). Um programa de estudos; tudo que uma organização deve aprender: a forma de trabalhar os objetivos comuns, sempre com o olhar no futuro. HSM Management, São Paulo, v. 2, n. 9, p. 74-80.

PETTIGREW, A. M (1987). Context and action in the transformation of the firms. Journal Management Studies, Vol 24, pp 649-670.

QUINTAS, P., LEFRERE, P., \& JONES, G (1997). Knowledge Management: a Strategic Agenda. Long range Planning, Vol.30, p. 385-391.

SENGE, Peter (1990). A Quinta Disciplina; arte, teoria e prática da organização de aprendizagem. São Paulo, Nova Cultural, p. 351.

TEECE, D (2000). Strategies for Managing Knowledge Assests: the Role of Firm Structure and Industrial Context, Long Range Planning, Vol. 33, pp 35-54.

TEIXEIRA FILHO, Jayme. (2000) Gerenciando o conhecimento. Rio de Janeiro: Senac.

TERRA, José Cláudio C. (2000). Gestão do Conhecimento: O grande desafio empresarial: uma abordagem baseada no aprendizado e na criatividade. São Paulo: Negócio Editora. 
WICK, C. W. \& LEON, L. (1995). From ideas to action: creating a learning organization. Human Resource Management, Summer, v. 34, n. 2, pp 299-311. 